\title{
Ganotherapy and Holistic Human System Is the Pathway of Holistic Health for Immediate Relief for COVID19
}

\author{
Sivakumaran Karuppiah ${ }^{1,2 *}$, Lim Siow Jin ${ }^{3}$ \\ ${ }^{1}$ Department of Research and Development of Natural Medicine, DXN Pharmaceutical Sdn. Bhd., Kulim, Malaysia \\ ${ }^{2}$ Association of Iridolology Practitioners Malaysia (IRHOL), Selangor, Malaysia \\ ${ }^{3}$ Association of Ganotherapy Practitioners Malaysia (GANOHM), Selangor, Malaysia \\ Email: *sivamal3176@gmail.com
}

How to cite this paper: Karuppiah, S. and Jin, L.S. (2020) Ganotherapy and Holistic Human System Is the Pathway of Holistic Health for Immediate Relief for COVID19. Open Journal of Preventive Medicine, 10 , 45-61.

https://doi.org/10.4236/ojpm.2020.103003

Received: March 2, 2020

Accepted: March 28, 2020

Published: March 31, 2020

Copyright () 2020 by author(s) and Scientific Research Publishing Inc. This work is licensed under the Creative Commons Attribution International License (CC BY 4.0).

http://creativecommons.org/licenses/by/4.0/

\begin{abstract}
This research of study continues personal research and professional practice in the Alternative Medicine (AM) has become an attractive and a popular issue between academicians and researchers in the last decades. AM is mostly used by individuals to support or to substitute the medical treatment. The studies from different disciplines have shown that the AM use is expanding all over the world but the popularity and the types of its use remain unclear. A qualitative study was conducted by treating a patient through several kinds of AM, receiving positive feedback from the patient. The overall data shows very good improvement since the AM becomes one of their parts of life to continue surviving on this earth with lots of challenges. Herbalist and vitamin supplements are the most popular and commonly used alternative medicine methods. Most people had used alternative medicine to improve their health conditions, thus eliminating the side effects of modern treatments. To supersede and recover or heal this chronic symptom, a combination of AM will be great to encounter it such as cancer, psoriasis, epilepsy, viral fever, etc. A combination of Ganotherapy and Knowledge of Holistic Human System enhances the AM era into battling these chronic cases and creates a powerful immune system to protect against it.
\end{abstract}

\section{Keywords}

Ganotherapy, Holistic Human System, Covid 19, Viral

\section{Introduction}

The use of alternative medicine (AM) has risen sharply in the last two decades, 
and has excited much research and great interest in the general public. The lifetime prevalence of AM use has been increasing since the 1950s, with yearly prevalence rates increasing moderately or holding steady from the late 1980s to 2013. Levels and patterns of use, however, are difficult to estimate because of a lack of consensus on the definition and measurement of AM. Consequently, the variability in definitions, classifications and measurements introduces thorny problems in fully documenting the prevalence levels, social group differentials, and use patterns of AM therapies.

"In 1977, the "30th World Health Organization (WHO) Assembly adopted a historic resolution urging governments to give adequate importance to the utilization of their traditional systems of medicine with appropriate regulations to suit their national health needs".

Both developing and developed countries have, thereafter, displayed greater interest and awareness in using traditional and indigenous health care resources in the implementation of their national health programmes. Immediately in the 1977 WHO resolution, a worldwide promotional effort for traditional and natural medicines was launched. The success of this promotion may be measured by the growing interest in these disciplines among many successful practitioners. There is a growing volume of articles and research papers on related themes appearing in scientific journals and lay publications: consequently, many scientific institutes and agencies are seeking to collaborate in research and training in traditional medicines."

Even though the AM is so popular and growing in the world, but from the modern perception (Allopathic) Medicine doctors are still lack of confidence on it. The culture and egoism are drastically changing since the Medical world start to accept the AM as part of their treatment. Thus, in the future this will be a part of the Medicine Syllabus for the young doctors to adapt both knowledge and supersede the overall way of creative thinking and handling patients.

\section{Methodology}

This Research based on the COVID 19 and the approach to knockdown the virus through balancing the immunity function of the patient and strengthens the body immune to fight the virus.

This paper, written on the 16 years direct experience of author 1 and 27 years experience of author 2, treated based on the real time result and testimonial from a patient who has been treated base on this AM treatment that is Ganotherapy and Holistic Human System. Here I would like to elaborate more on the treatment and analysis been made for each patient.

To knock down the virus we need to improve the immunity function of the body not to find cures for the diseases. We have to work backwards prepare the system to fight disease not to find cures for the disease.

\subsection{Ganoderma and Ganotherapy Treatment}

In ancient period, Chinese kings used this Ganoderma which gives a positive ef- 
fect on their health. They lived many years due to the increment of their immunity power. Today, World Health Organization (WHO) has proved the Ganoderma as an excellent food and medicine. The biologist also grows the red mushroom by giving suitable temperature in green houses. Today the history about Ganoderma has become truth in this world [1] [2]. Ganoderma is known as Lingzhi in Chinese, are common using Chinese medicines with excellent beneficial health effects. Triterpenes and polysaccharides are usually considered as their main active components. However, the content of triterpenes differs significantly between the two species of Ganoderma [3].

Ganoderma is known as red mushrooms, which have medicinal power to prevent the human from different internal and external diseases [4]. The research of Ganoderma is known as Ganotherapy. There are different kinds of mushroom found on this earth. Mostly the people are taking poisonous mushroom which kills the internal parts of the body and slowly he or she dies. Ganoderma has become the powerful medicine on Earth. It is only found in high mountains and near the hills and in the shade of sun. There are different types of Ganoderma which is also called Gano such as Liver Gano, Peacock Gano, Heart Gano, Kimshen Gano, Brain Gano, and Ruyi Gano.

Chinese tradition proclaims that Ganoderma is also called "miraculous Zhi", or "auspicious herb" and is considered to "symbolize happy augury, and to bespeak good fortune, good health and longevity, even immortality" [5]. As early as 800 years ago in the Yuan Dynasty (A.D., 1280-1368) Ganoderma has been represented in paintings, carvings, furniture, carpet design, jewellery, perfume bottles and many more creative artworks [6]. In two famous Chinese herb medical books, Shen Nong Ben Cao Jing (25-220 A.D., Eastern Han Dynasty) and Ben Cao Gang Mu (1590 A.D., Ming Dynasty), there were six known species of Ganoderma (Ling Zhi) in China at that time, whereas now more than 250 species have been described [7] [8].

Over the past century, a number of synthetic antimicrobial agents have been discovered and developed, but drug resistance and toxicity are still the major hindrances to gaining successful therapeutic outcomes in many instances. Herbal medicines may represent a safe and useful supplement to existing chemotherapeutic therapies for the management of infectious diseases. Ganoderma has traditionally been used to treat chronic infectious diseases, such as chronic hepatitis and bronchitis in Asia, when it is administered alone or more often in combination with chemotherapeutic agents. Preclinical (in vitro and in vivo animal) studies indicate that Ganoderma exhibits a broad spectrum of antibacterial and antiviral activities, whereas data in human beings are scanty. Polysaccharides or triterpenoids from Ganoderma showed activities against Herpes simplex virus, Hepatitis B virus, HIV, and Epstein-Barr virus in vitro or in animal models. Ganoderma species also contain antibacterial constituents inhibiting gram-positive and/or gram-negative bacteria in vitro [9]. 


\subsection{Ganoderma and Ganotherapy History in Malaysia}

The treatment fundamentally utilized based on the Ganotherapy method that introduce by Dr. Lim Siow Jin and also a founder of DXN Pharmaceutical Sdn. Bhd. The company produces 6 types of Ganoderma. The production of Ganoderma using an exact reproduction of the mother plant itself. This is to control on the high quality species is possible. DXN is using this method of Organic Cultivation Method with 100\% organic farming, no chemical fertilizer, insecticide, hormone, etc. The mixture to produce used highly nutritional cultivation method, using paddy, brown rice powder etc.

All the production certified by all the necessary approvals from all certification such as KKM, TGA, ISO14001, HACCP, ISO9001, HALAL, GMP and etc. This is to verify the quality and therapeutics properties are well taken care upon production. Currently, more than 180 countries are benefitting from the Ganoderma that exported from Malaysia. Ganoderma is called king of herbs. This can be searched any website due to the high natural contains of essential nutrients.

In the world today, the majority of the population is in the state of "pre-illness" due to environmental pollution, stresses and unhealthy lifestyle such as consuming diets which are high in fats, cholesterol, sugar, salt and chemical additives. Ganoderma has drawn folk's attention in improving health status in which it could ameliorate ailments and lessen diseases risk [10]. Under these circumstances, it is wise to prevent any deterioration in health rather than seek a cure after illness prevails as the saying goes: "Prevention is better than cure".

Ganotherapy is one of the holistic approaches to alternative complementary medicine. The essential principle is that our body is the best doctor. Our body immune system when at its optimal condition is able to fight various diseases at one time, knowing the priority and without having side effects. All we see or feel is the reactions as it gets rid of the toxins and cure the illnesses. In Ganotherapy, It uses Ganoderma extracts from the fruit body and its mycelium to gain health.

Ganoderma contains more than 400 bioactive compounds, including polysaccharides, triterpenoids, fatty acids, amino acids, nucleosides, proteins, alkaloids, vitamins, minerals and dietary Fiber which are essential nutritional elements to build the body strong and healthy [11]. These Important listed five active elements which are available in Ganoderma for therapeutic benefits are as follows. These five active elements in single herb make Ganoderma a special herb.

\subsection{The 4 Basic Principles of Ganotherapy}

The 4 basic principles as being prescribed clearly in the Ganotherapy book [1]. The principles listed as per below.

1) Illnesses are caused by 2 sources; Toxins in our body and disharmony in body functions.

2) Ganoderma does not cure illness, but it helps to balance up our body system and improve immunity against diseases. 
3) Any reaction that takes place is caused by our body system and not by the intake of Ganoderma.

4) The dosage of Ganoderma taken is irrelevant to diseases.

All the essential properties are very good in terms benefitting human body to be strengthened and ability to fight diseases. Lots of research done on it and more than 20 thousand research papers, journals has been published worldwide. Figure 1 below explained about all the various components of essential vitamin and minerals contain in Ganoderma.

\subsection{Holistic Human System}

As an ordinary human being we totally forgot on the system effectively and immunity to fight against any diseases whether it was bacteria or viruses. The body acts as a best doctor by itself (Auto Immune function). Our body immune system when at its optimal condition is able to fight various diseases at one time, knowing the priority and without having side effects. All we see or feel is the reactions as it gets rid of the toxins and cure the illnesses.

The Human system develops from single cell $<$ tissue $<$ organ $<$ system and lastly become a complete human body. It comprises 11 systems of Integumentary,

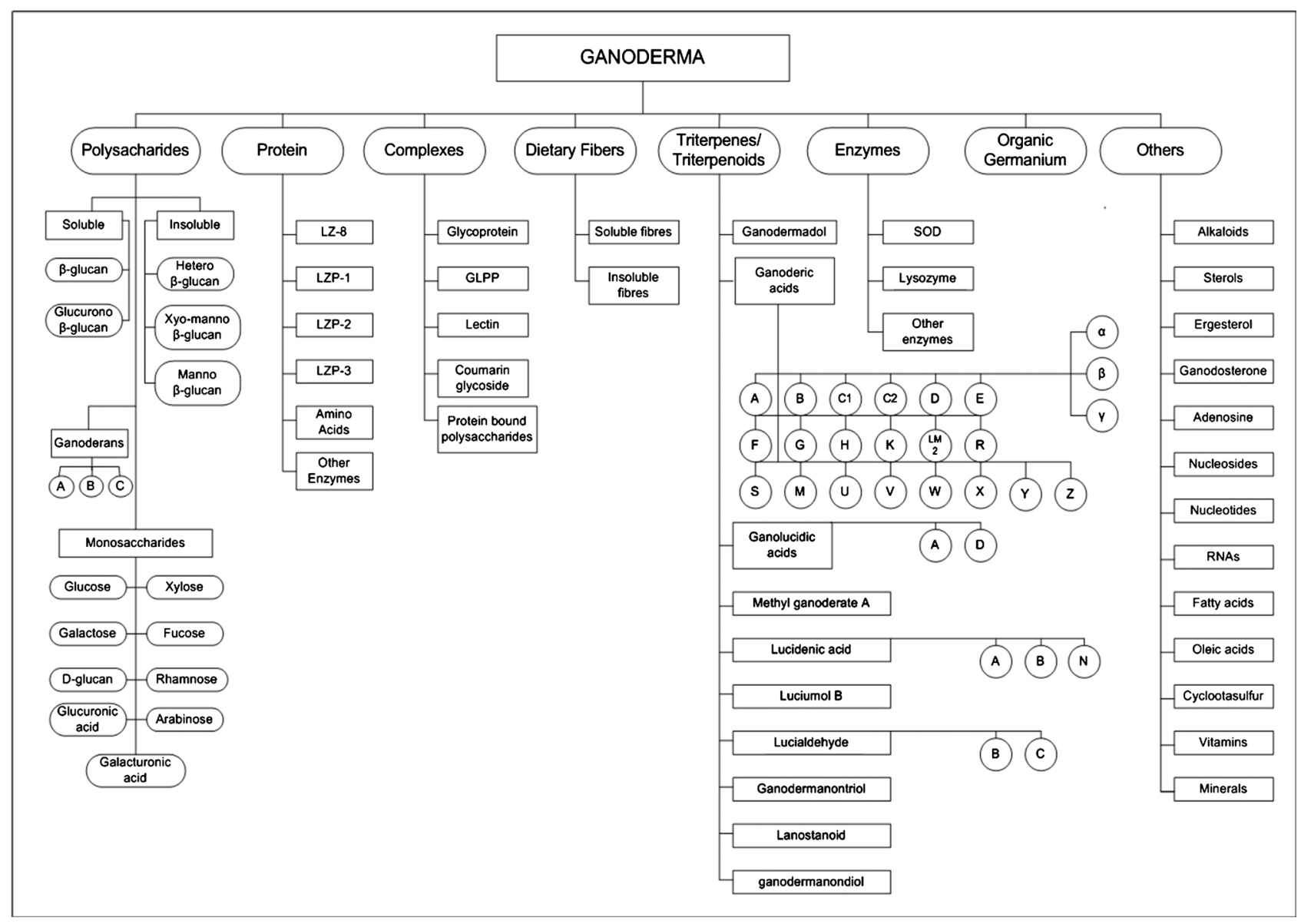

Source: Persuasive biologically active constituents and their health endorsement [12].

Figure 1. Breakdown of bioactive compounds of Ganoderma. 
skeletal, lymphatic, respiratory, muscular, nervous, digestive, urinary, endocrine, cardiovascular and reproductive system.

We must understand if we want to treat a patient, we need to treat the system not the organ itself. The entire organ connected directly to the system and forms a complete human. Hence, if we try to treat the organ itself the other system that connected to that organ will be interrupted and the problem spread to other parts of the system. In Holistic Human System we train and does knowledge transfer to the patients in their system. The patient shall understand how is the system functionalities and how it's ability to repair itself with the help of the Ganotherapy principles.

Holistic human systems are playing an immense role with the combination of a mixture of alternative medicines such as Ganotherapy. These three main components are a booster to fight any diseases and it is very important to be increased in one of the patients who suffer.

Whole world need to accept that two phrases keep on telling by almost all the doctors neither Modern Allopathic doctors or AM Doctors that the first one is "Body is the best doctors" and the second one is "Food Medicine".

There are some quotes by several scientists and famous nutritionist such as:

"Let food be thy medicine and medicine be thy food."

--Hippocrates, the father of modern medicine 2500 years ago.

"The doctor of the future will no longer treat the human frame with drugs, but rather will cure and prevent disease with nutrition."

--Thomas Edison, inventor of the light-bulb, world record holder of 1093 patents, founder of GE (General Electric).

Based on the ancient quotes Holistic Medicine already exists in this world 2500 years ago. It seems we all forgot on the outcome and the cures of this Holistic approach. There are lots of people celebrating their $100^{\text {rd }}$ Birthday every day. They are very strong to live in this world with a strong immune system. 5000 years ago, human was using holistic approach to treat them as a food in their daily life cycle. The way we eat and the way we drink water, everything has been organized properly. If we do some analysis using animals, none of the animals are eating and drinking water at the same time. It's only eat when it's feel hungry and only drinks when it feels thirsty, even though fish in the sea also eat without drinking water. You can operate and check whether there is water or not. This is just an example of some research about animal that following a proper way of eating and drinking, not human. By changing this habit, most of the disease can be cured by our body. This is the one of the approaches of knowledge transfer used in this approach called Human Holistic System.

\subsection{Ganoderma Approach in Viral and Bacterial Infections}

The goal of research in the treatment of viral and bacterial infections is the discovery of agents that specifically inhibit viral and bacterial multiplication without affecting normal cells. The undesired side effects of antibiotics and antiviral 
and the appearance of resistant and mutant strains make the development of new agents an urgent requirement.

This has led researchers to investigate the antibacterial and antiviral activity of medicinal plants and fungi [6] [13]. Isolation of various water- and methanol-soluble, high-molecular-weight PBPs from Ganoderma showed inhibitory effects on herpes simplex virus type 1 (HSV-1), herpes simplex virus type 2 (HSV-2), and vesicular stomatitis virus (VSV) New Jersey strain in a tissue culture system. Using the plaque reduction method, a significant inhibitory effect was seen at doses that showed no cytotoxicity [14] [15].

In addition, there was a marked synergistic effect when PBP from Ganoderma was used in tissue culture in conjunction with antiherpetic agents, acyclovir or vidarabine, and with IFN- $\alpha$ [15] [16]. Similar results were shown in HSV-1 and HSV-2 with a GLPG isolated from the mycelia of Ganoderma [17]. The cells were treated before, during, and after infection, and viral titers in the supernatant of cell culture 48 hours post infection was determined. The antiviral effects of the GLPG were more remarkable before viral treatment than after treatment. Although the mechanism was not defined, the authors concluded that GLPG inhibits viral replication by interfering with early events of viral adsorption [18].

Some triterpenes from Ganoderma have also been reported to have an inhibitory effect against human immunodeficiency virus (HIV)-1 protease activity, with IC50 values ranging from 20 to more than $1000 \mu \mathrm{M}$; however, not all of the examined triterpenes showed anti-HIV activity [19]. In another study, a ganoderic acid isolated from Ganoderma showed inhibitory effects on the replication of hepatitis B virus (HBV) in HepG2215 cells (HepG2-HBV-producing cell line) over 8 days. Production of HBV surface antigen (HBsAg) and HBV e antigen (HBeAg) were, respectively, $20 \%$ and $44 \%$ of controls without ganoderic acid treatment [20].

Some small studies in human patients have also reported beneficial effects of lingzhi intake. A dried hot water extract of Ganoderma has taken orally (equivalent to 36 or $72 \mathrm{~g}$ of dried mushrooms per day) was used as the sole treatment for postherpetic (varicella zoster virus) neuralgia in 4 elderly patients. This treatment was reported to dramatically decrease pain and promote the healing of lesions, without any toxicity even at very high doses [21]. In another study, a mixture of Ganoderma with other herbs improved recovery time in patients with herpes genitalis $(n=15)$ and herpes labiallis $(n=13)$ [22].

For evaluating the antibacterial effects of the mushroom, several in vitro and in vivo animal studies using Ganoderma were performed. Mice injected with Ganoderma extract ( $2 \mathrm{mg} /$ mouse) 1 day prior to injection with Escherichia coli showed markedly improved survival rates ( $>80 \%$ compared to $33 \%$ in controls); [23]. In an in vitro study that used the disk assay [24], a chloroform extract of Ganoderma was investigated for its antibacterial effect on gram-positive bacteria (Bacillus subtilis, Staphylococcus aureus, Enterococcus faecalis) and gram-negative bacteria (E. coli, Pseudomonas aeruginosa). Results showed that the extract had 
growth-inhibitory effects on two of the gram-positive bacteria with a minimal inhibitory concentration (MIC) of $8 \mathrm{mg} / \mathrm{mL}$ for Staphylococcus aureus and Bacilus subtilis. In another in vitro study, the direct antimicrobial effect of a Ganoderma water extract was examined against 15 species of bacteria alone and in combination with 4 kinds of antibiotics [25]. Ganoderma was found to be more effective than antibiotics against E. coli, Micrococcus luteus, Staphylococcus aureus, Bacillus cereus, Proteus vulgaris, and Salmonella typhi, but less effective against other species tested. The antimicrobial combination of Ganoderma with four commonly used antibiotics [25] resulted in an additive or synergistic effect in most, but not all, instances, with apparent antagonism against cefazolin and ampicillin effects on Proteus vulgaris.

To date, the antimicrobial components of the tested crude extracts have not been identified, although antimicrobial polysaccharides have been identified in other fungi and plant terpenes have been reported to have antimicrobial activity [6] [13]. In addition, the bioavailability of putative antimicrobial components of Ganoderma has not been established. Nonetheless, Ganoderma offers a potentially effective therapy. There is also the implication that combination therapy may be more safe and cost effective, as lower amounts of cytotoxic antiviral and antibacterial drugs could be used with a concomitant decrease in the risk of side effects.

\section{Findings and Combination of Alternative Medicine}

Based on the evidence based report from high impact journals from worldwide it's confirmed that Ganoderma can help COVID 19 patients to boost their immune to make the body has all the ability to perform a natural antibody to fight against the virus.

Ganoderma is not the form of treatment for curing the Covid 19 virus, thus it help the body system to perform nutrition balancing and help the body to fight against the virus. This is a way to fight backwards that instead of finding cures for diseases let the body to be strengthened so it has all the ability to fight the virus.

This is the Holistic method to "Heal without healing theory". Ganoderma can work together with the allopathic medicine and no side effect or impact happen to the body. Integrated medication is called Ganotherapy and it's the best work with current mainstream.

\subsection{Combination Therapy of AM to Strengthen the Immune System}

The main focus of the treatment as a "FOOD" for the patients and not as the medication allopathic treatment for the COVID 19 patients. Ganoderma can be the first line or second line treatment to knock down the virus and will act as food to strengthen the immune system. There is also some other nature Holistic medication such as Vitamin C therapy, Andrographis paniculata (in Malay 
Language called "Hempedu Bumi", In Tamil Language called "Nila Vembu") and Nigella sativa or Black Cumin (in Malay called Halbata Saudah, In Tamil Language called "Karum Siragam").

The Combination of these Natural sources to be strengthens the immune system of the patient and non patient for the normal person or Frontline medical personnel.

1) Ganoderma (King of Herbs)

2) Black Cumin (Nigella sativa/Habatas Saudah/Black seed)

3) Andrographis paniculata (Hempedu Bumi)

4) Roselle

This is the combination therapies we can prescribe to the Covid 19 patients and to normal people or medical Frontline people, which can strengthen the immunity and the ability to perform duties and take care patients without any worries.

\subsection{Black Cumin Properties and Clinical Trials}

Nigella sativa (black seed or black cumin), which belongs to the Ranunculacea family, is an annual herb with many pharmacological properties. Among its many active constituents, thymoquinone (TQ) is the most abundant constituent of the volatile oil of Nigella sativa (NS) seeds, and it is the constituent to which most properties of this herb are attributed [26].

As for lower respiratory tract illnesses (LRTI), [26] investigated the antiasthmatic effects of NS boiled extract (50 and $100 \mathrm{mg} / \mathrm{kg}$ ), theophylline $(5 \mathrm{mg} / \mathrm{kg}$ ), and salbutamol $(200 \mu \mathrm{g})$ [26]. In that study, 15 asthmatic patients were recruited, and each patient received one of these 4 treatments in random order at intervals of 48 hours for 2 weeks. The results of that study demonstrated that in spite of the fact that both doses of NS boiled extract showed bronchodilatory effects, their efficacies for pulmonary function test (PFT) elevation were less than those of theophylline and salbutamol. The results also revealed the prophylactic effects of NS boiled extract on adult asthmatic patients.

In another study, over a 3-month period, the daily intake of $15 \mathrm{~mL} / \mathrm{kg}$ of $0.1 \%$ NS boiled extract led to more impressive improvements in the PFT parameters and alleviations of the symptoms of asthma than the intake of the placebo solution theophylline and salbutamol [26]. Ahmad et al. conducted a study on 5- to 15-year-old LRTI patients with wheezing and investigated the beneficial impacts of the standard treatment alone and the standard treatment combined with the use of NS oil [27]. The result of this study concluded that the standard treatment when administered with the NS oil ( $0.1 \mathrm{mg} / \mathrm{kg}$ for 14 days) had more beneficial effects in reducing the pulmonary index and improving the peak expiratory flow rate [27].

Infection with Hepatitis C Virus (HCV) often leads to chronic hepatitis, which, in turn, results in liver cirrhosis and hepatocellular carcinomas. A study conducted in Egypt on HCV patients demonstrated that ethanolic extracts of NS 
and Zingiber officinale ( $Z$. officinale), alone and together, had beneficial effects on HCV patients; i.e., their liver function was improved and the viral load was decreased [28]. In that study, a mixture of these extracts was observed to be more effective than each one alone. Patients included in that study were treated with capsules containing $500 \mathrm{mg}$ of NS and/or $Z$. officinale twice daily for one month. In a similar study, HCV patients received capsules of NS oil $(450 \mathrm{mg})$ three times a day over a 3-month period. That treatment led to the same results reported in Reference [28], i.e., decreased viral load and improved liver function [29].

Onifade et al. confirmed that treatment of a sero-positive human immunodeficiency virus (HIV) infected man with NS concoction $(10 \mathrm{~mL}$ twice/day for six months) resulted in the reduction of the viral load to an undetectable level in 3 months, an elevation of the CD4 count, an alleviation of the symptoms, and a sustained sero-reversion [30]. Similarly, another study conducted by the same author on a sero-positive HIV infected woman revealed the efficacy of NS and honey therapy (10 mL thrice/day for 1 year) for sustained sero-reversion [31]. These effects can be ascribed to the probable virucidal activity of NS [31].

The Helicobacter pylori (H. pylori) bacterium can cause many diseases, such as peptic ulcers and gastric cancer. Infection with $H$. pylori has a high prevalence worldwide. Salem et al. stated that in a four-week course, the efficacy of NS powder ( $2 \mathrm{~g} /$ day) administered together with omeprazole to eradicate an $H$. $p y$ lori infection in non-ulcer dyspeptic patients was relatively the same as that of triple therapy, although $1 \mathrm{~g}$ /day or $3 \mathrm{~g}$ /day of NS powder given together with omeprazole was not as effective, indicating that the optimal dose of NS was 2 g/day [30]. (Triple therapy includes clarithromycin, amoxicillin, and omeprazole).

Some effects of NS, such as its hypoglycemic, hypolipidemic and bronchodilatory effects have been sufficiently studied and are sufficiently understood to allow for the next phase of clinical trials or drug developments. In this study, we also reviewed other advantages of NS, e.g., its antimicrobial properties, anti-nociceptive and anti-epileptic impacts, etc. We found that the side effects of this herbal medicine did not appear serious, so it can be applied in clinical trials because most of its major effects have been shown to be beneficial.

\subsection{Andrographis paniculata Properties and Clinical Trials}

In light of the continued popularity of herbal medicine [32], an effective and well-tolerated herbal medication for the prevention and treatment of acute respiratory infections would be a welcome addition to the therapeutic repertoire. The leaves of Andrographis paniculata, popular in Scandinavia as a cold and influenza remedy, are used traditionally in Ayurvedic, Thai and Chinese medicine to treat fever associated with infectious diseases. Pharmacological studies suggest anti-inflammatory [33] [34], antipyretic [35] [36], antiviral [37] and immunostimulatory [38] properties. The aim of this review was to systematically assess 
the efficacy and safety of Andrographis paniculata in the treatment and prevention of upper respiratory tract infections.

Andrographis paniculata is also very effective herbal medicine to knock down the Dengue Virus. Dengue is caused by any one of four related viruses transmitted by mosquitoes. Currently, there is no vaccine to prevent infection with dengue virus and the most effective protective measures are take preventive measures by keeping and maintaining clean environments. Early recognition and prompt supportive treatment can substantially lower the risk of medical complications and death. In this study, the maximum nontoxic dose (MNTD) of the Andrographis paniculata plant was determined by testing the ethanolic extracts against Vero cells in vitro. Antiviral assay based on cytopathic effects denoted by the degree of inhibition upon treating DENV 1-4-infected Vero cells with MNTD of Andrographis paniculata has the most antiviral inhibitory effects. These results were further verified by an in vitro inhibition assay using MTT and RT-PCR, in which 55\% - 97\% of cell viability were recorded in DENV-1-4-infected cells in different duration. Ethanolic extracts treated with dengue VLs also showed a significant changes which were reflected in RT PCR assay [39].

In conclusion, these data suggest that Andrographis paniculata may be a promising treatment for the alleviation of subjective symptoms of acute upper respiratory tract infection and antiviral properties that can eliminate the virus from the body. In addition, short-term treatment, at recommended doses, is associated with few reports of adverse events. In light of the lack of effective therapeutic options for acute upper respiratory tract infection, Andrographis paniculata is an herbal treatment option that is worthy of consideration for further research.

\subsection{Roselle Properties and Clinical Trials}

Stated the entire test cases 2019 novel corona virus (2019-nCoV) infected pneumonia, namely severe acute respiratory infection (SARI) has caused global concern and emergency. There is a lack of effective targeted antiviral drugs, and symptomatic supportive treatment is still the current main treatment for SARI.

Vitamin C is significant to human body and plays a role in reducing inflammatory response and preventing the common cold. In addition, a few studies have shown that vitamin $\mathrm{C}$ deficiency is related to the increased risk and severity of influenza infections. Time being Vitamin $\mathrm{C}$ that used for medical is synthetically design and less effective for treating the patients. Holistic Medicine suggested live vitamin $\mathrm{C}$ from Roselle is purely organic and tested natural. It contains not only vitamin $C$ but lots of essential minerals and trace element with several vitamins and minerals as per Table 1 .

The calyces are also rich in vitamins, especially ascorbic acid [40]. Ascorbic acid is an essential dietary component. Various workers have reported variable content, suggesting the type of soil influences its ash and mineral content causing 
Table 1. Nutritional composition of $100 \mathrm{~g}$ fresh Roselle calyces, leaves and seeds.

\begin{tabular}{cccc}
\hline Constituents & Fresh Calyces & Fresh Leaves & Seeds \\
\hline Moisture & $9.20 \mathrm{~g}$ & $85.60 \mathrm{~g}$ & $8.2 \mathrm{~g}$ \\
Protein & $1.15 \mathrm{~g}$ & $3.30 \mathrm{~g}$ & $19.6 \mathrm{~g}$ \\
Fat & $2.61 \mathrm{~g}$ & $0.30 \mathrm{~g}$ & $16.0 \mathrm{~g}$ \\
Fiber & $12.00 \mathrm{~g}$ & $10.00 \%$ & $11.0 \mathrm{~g}$ \\
Energy & $44 \mathrm{kcal}$ & $43 \mathrm{kcal}$ & $411 \mathrm{kcal}$ \\
Ash & $6.90 \mathrm{~g}$ & $1.00 \mathrm{~g}$ & $7.00 \mathrm{~g}$ \\
Calcium & $12.63 \mathrm{mg}$ & $213.00 \mathrm{mg}$ & $356 \mathrm{mg}$ \\
Phosphorus & $273.20 \mathrm{mg}$ & $93.00 \mathrm{mg}$ & $462 \mathrm{mg}$ \\
Iron & $8.98 \mathrm{mg}$ & $4.80 \mathrm{mg}$ & $4.2 \mathrm{mg}$ \\
Carotene & $0.03 \mathrm{mg}$ & $4135 \mu \mathrm{g}$ & - \\
Riboflavin & $0.28 \mathrm{mg}$ & $0.45 \mathrm{mg}$ & $0.15 \mathrm{mg}$ \\
Niacin & $3.77 \mathrm{mg}$ & $1.2 \mathrm{mg}$ & $1.4 \mathrm{mg}$ \\
Ascorbic Acid & $6.70 \mathrm{mg}$ & $54 \mathrm{mg}$ & trace \\
Carbohydrates & $10.00 \mathrm{~g}$ & $9.20 \mathrm{~g}$ & $51.3 \mathrm{~g}$ \\
\hline
\end{tabular}

Sources: [41] [48] [49] [50].

variations within the same species [41] [42] [43] [44]. The antimicrobial activity, antibacterial and cytotoxicity a study in dose-dependent manner has have also been studied [45] [46]. Moreover, the antimicrobial activity on isolated from food, veterinary, and clinical samples have indicated that Roselle extract contains potential antimicrobials in foods [47].

\section{Conclusions}

In health care, even a small problem or minor disease should be given full attention because a small problem may sometimes become bigger health problems in some days. Therefore AM Holistic and Allopathic Treatment shall joint hand to hand to fight the virus that shakes the whole world. AM Holistic and Ganotherapy can be used by any kind of people no matter on gender, religion or age and the results obtained from AM are always a success.

There are thousands of journals and studies have been conducted by various scholars, universities, research centre on the effect of Ganoderma especially in Malaysia, China, Japan, Korea, India, Canada, US and etc. As per our knowledge personally we have treated thousands of patients with various kinds of respiratory issues. Expected and the satisfied result promises based on the Holistic natural treatment that categorized under food by The Dietary Supplement Health and Education Act of 1994 ("DSHEA"), is a 1994 statute of United States Federal legislation which defines and regulates dietary supplements. Under the act, supplements are effectively regulated by the FDA for Good Manufacturing Practices under 21 CFR Part 111. 
Last but not least, we must stress that the work presented here is based wholly on Author 1 as 16 years experience and Author 2 with 27 years of experience, from direct contact with patients, colleagues, referenced when appropriate. The clinical and research-based work presented in this paper is true to our knowledge base at the time of publication, although there are, always, much we can all learn and apply to help patients and their families. We encourage suggestions and discussion within this field.

\section{Acknowledgements}

Here we would like express our thanks to DXN Pharmaceutical Sdn Bhd who grant the publication of this paper, Association of Ganotherapy Practitioners Malaysia and Association of Iridology Practitioners of Malaysia to complete the overall research paper.

\section{Conflicts of Interest}

The authors declare no conflicts of interest regarding the publication of this paper.

\section{References}

[1] Jin, L.S. (2010) Ganotherapy: The Miraculous King of Herbs.

[2] Jin, L.S. (2003) Ganotherapy: Ganoderma lucidum the Miracle Mushroom, King of Herb and Herb of Kings for Health.

[3] Xie, J., et al. (2012) Comparison of Polysaccharides from Two Species of Ganoderma Molecules.

[4] Lindequist, U., Niedermeyer, T.H. and Jülich, W.D. (2005) The Pharmacological Potential of Mushrooms. Evidence-Based Complement Alternative Medicine, 2, 285-299. https://doi.org/10.1093/ecam/neh107

[5] Wasson, R.G. (1968) Divine Mushroom of Immortality. Harcourt Brace Jovanovich, Los Angeles, 80-93.

[6] Wasser, S.P. and Weis, A.L. (1999) Medicinal Properties of Substances Occurring in Higher Basidiomycetes Mushrooms: Current Perspectives. International Journal Medicinal Mushrooms, 1, 31-62. https://doi.org/10.1615/IntJMedMushrooms.v1.i1.30

[7] Moncalvo, J.M., Wang, H.F., Wang, H.H. and Hseu, R.S. (1994) Molecular Studies in the Ganoderma lucidum Complex. In: 94' International Symposium on Ganoderma Research, Beijing Medical University Press, Beijing, 12-13.

[8] Ryvarden, L. (1994) Can We Trust Morphology in Ganoderma? Proceedings of Contributed Symposium, 14-21 August 1994, 19-24.

[9] Gao, Y.H., et al. (2007) Antimicrobial Activity of the Medicinal Mushroom Ganoderma. Food Reviews International, 21, 211-229. https://doi.org/10.1081/FRI-200051893

[10] Ansor, M., et al. (2013) Anti-Angiotensin Converting Enzyme (ACE) Proteins from Mycelia of Ganoderma lucidum (Curtis) P. Karst. BMC Complementary and Alternative Medicine, 13, Article No. 256. http://www.biomedcentral.com/1472-6882/13/256 https://doi.org/10.1186/1472-6882-13-256 
[11] Cör, D., Knez, Ž. and Knez, H.M. (2018) Antitumour, Antimicrobial, Antioxidant and Antiacetylcho Linesterase Effect of Ganoderma lucidum Terpenoids and Polysaccharides: A Review. Molecules, 23, 649.

https://doi.org/10.3390/molecules23030649

[12] Ahmad, M.F. (2018) Ganoderma lucidum: Persuasive Biologically Active Constituents and Their Health Endorsement. Department of Clinical Nutrition, College of Applied Medical Sciences, Jazan University, Jazan, 507-519.

https://doi.org/10.1016/j.biopha.2018.08.036

[13] Zhong, J.J. and Xiao, J.H. (2009) Secondary Metabolites from Higher Fungi: Discovery, Bioactivity and Bioproduction. Advances in Biochemical Engineering/Biotechnology, 113, 79-150. https://doi.org/10.1007/10_2008_26

[14] Eo, S.K., Kim, Y.S., Lee, C.K. and Han, S.S. (1999) Antiviral Activities of Various Water and Methanol Soluble Substances Isolated from Ganoderma lucidum. Journal of Ethnopharmacology, 68, 129-136.

https://doi.org/10.1016/S0378-8741(99)00067-7

[15] Oh, K.W., Lee, C.K., Kim, Y.S., Eo, S.K. and Han, S.S. (2000) Antiherpetic Activities of Acidic Protein Bound Polysacchride Isolated from Ganoderma lucidum Alone and Incombination with Acyclovir and Vidarabine. Journal of Ethnopharmacology, 72, 221-227. https://doi.org/10.1016/S0378-8741(00)00254-3

[16] Kim, Y.S., Eo, S.K., Oh, K.W., Lee, C.K. and Han, S.S. (2000) Antiherpetic Activities of Acidic Protein Bound Polysaccharide Isolated from Ganoderma lucidum Alone and in Combinations with Interferons. Journal of Ethnopharmacology, 72, 451-458. https://doi.org/10.1016/S0378-8741(00)00263-4

[17] Liu, J. and Ye, B.L. (2005) Possible Mode of Action of Antiherpetic Activities of a Proteoglycan Isolated from the Mycelia of Ganoderma lucidum in Vitro. Journal of Ethnopharmacology, 95, 265-272. https://doi.org/10.1016/j.jep.2004.07.010

[18] Li, Z., Liu, J. and Zhao, Y. (2005) Possible Mechanism Underlying the Antiherpetic Activity of a Proteoglycan Isolated from the Mycelia of Ganoderma lucidum in Vitro. Journal of Biochemistry and Molecular Biology, 38, 34-40. https://doi.org/10.5483/BMBRep.2005.38.1.034

[19] El-Mekkawy, S., Meselhy, M.R. and Nakamura, N. (1998) Anti-HIV-1 and Anti-HIV-1-Protease Substances from Ganoderma lucidum. Phytochemistry, 49, 1651-1657. https://doi.org/10.1016/S0031-9422(98)00254-4

[20] Li, Y.Q. and Wang, S.F. (2006) Anti-Hepatitis B Activities of Ganoderic Acid from Ganoderma lucidum. Biotechnology Letters, 28, 837-841. https://doi.org/10.1007/s10529-006-9007-9

[21] Hijikata, Y. and Yamada, S. (1998) Effect of Ganoderma lucidum on Postherpetic Neuralgia. The American Journal of Chinese Medicine, 26, 375-381.

https://doi.org/10.1142/S0192415X98000415

[22] Hijikata, Y., Yamada, S. and Yasuhara, A. (2007) Herbal Mixtures Containing the Mushroom Ganoderma lucidum Improve Recovery Time in Patients with Herpes Genitalis and Labialis. The Journal of Alternative and Complementary Medicine, 13, 985-987. https://doi.org/10.1089/acm.2006.6297

[23] Ohno, N., Miura, N.N., Sugawara, N., Tokunaka, K., Kirigaya, N. and Yadomae, T. (1998) Immunomodulation by Hot Water and Ethanol Extracts of Ganoderma $1 u$ cidum. Pharmaceutical and Pharmacological Letters, 4, 174-177.

[24] Keypour, S., Riahi, H., Moradali, M.F. and Rafati, H. (2008) Investigation of the Antibacterial Activity of a Chloroformextract of Lingzhi or Reishi Medicinal Mushroom, Ganoderma lucidum (W. Curt.: Fr.) P. Karst. (Aphyllophoromycetideae). 
International Journal of Medicinal Mushrooms, 10, 345-349. https://doi.org/10.1615/IntJMedMushr.v10.i4.70

[25] Yoon, S.Y., Eo, S.K., Kim, Y.S., Lee, C.K. and Han, S.S. (1994) Antimicrobial Activity of Ganoderma lucidum Extract Alone and in Combination with Some Antibiotics. Archives of Pharmacal Research, 17, 438-442. https://doi.org/10.1007/BF02979122

[26] Tavakkoli, A., Mahdian, V., Razavi, B.M. and Hosseinzadeh, H. (2017) Review on Clinical Trials of Black Seed (Nigella sativa) and Its Active Constituent, Thymoquinone. Journal of Pharmacopuncture, 20, 179-193. https://doi.org/10.3831/KPI.2017.20.021

[27] Boskabady, M.H., Javan, H., Sajady, M. and Rakhshandeh, H. (2007) The Possible Prophylactic Effect of Nigella sativa Seed Extract in Asthmatic Patients. Fundamental \& Clinical Pharmacology, 21, 559-566. https://doi.org/10.1111/j.1472-8206.2007.00509.x

[28] Ahmad, J., Khan, R.A. and Malik, M.A. (2009) A Study of Nigella sativa Oil in the Management of Wheeze Associated Lower Respiratory Tract Illness in Children. African Journal of Pharmacy and Pharmacology, 3, 248-251.

[29] Abdel-Moneim, A., Morsy, B.M., Mahmoud, A.M., Abo-Seif, M.A. and Zanaty, M.I. (2013) Beneficial the Rapeutic Effects of Nigella sativa and/or Zingiber officinale in HCV Patients in Egypt. EXCLI Journal, 12, 943-955.

[30] Onifade, A.A., Jewell, A.P. and Okesina, A.B. (2015) Seronegative Conversion of an HIV Positive Subject Treated with Nigella sativa and Honey. African Journal of Infectious Diseases, 9, 47-50. https://doi.org/10.4314/ajid.v9i2.6

[31] Barakat, E.M.F., El Wakeel, L.M. and Hagag, R.S. (2013) Effects of Nigella sativa on Outcome of Hepatitis C in Egypt. World Journal of Gastroenterology, 19, 2529-2536. https://doi.org/10.3748/wjg.v19.i16.2529

[32] Salem, E.M., Yar, T., Bamosa, A.O., Al-Quorain, A., Yasawy, M.I. and Alsulaiman, R.M. (2010) Comparative Study of Nigella sativa and Triple Therapy in Eradication of Helicobacter pylori in Patients with Non-Ulcer Dyspepsia. Saudi Journal of Gastroenterology, 16, 207-214. https://doi.org/10.4103/1319-3767.65201

[33] Kessler, R.C., Davis, R.B., Foster, D.F., Van Rompay, M., Walters, E.E. and Wilkey, S.A. (2001) Long Term Trends in the Use of Complementary and Alternative Medical Therapies in the United States. Annals of Internal Medicine, 135, 262-268. https://doi.org/10.7326/0003-4819-135-4-200108210-00011

[34] Shen, Y.C., Chen, C.F. and Chiou, W.F. (2002) Andrographolide Prevents Oxygen Radical Production by Human Neutrophils: Possible Mechanism (s) Involved in Its Anti-Inflammatory Effect. British Journal of Pharmacology, 135, 399-406. https://doi.org/10.1038/sj.bjp.0704493

[35] Amroyan, E., Gabrielian, E., Panossian, A., Wikman, G. and Wagner, H. (1999) Inhibitory Effect of Andrographolide from Andrographis paniculata on PAF-Induced Platelet Aggregation. Phytomedicine, 6, 27-31. https://doi.org/10.1016/S0944-7113(99)80031-2

[36] Madav, S., Tripathi, H.C., Tandan, S.K. and Mishra, S. (1995) Analgesic, Antipyretic and Antiulcero-Genic Effect of Andrographolide. Indian Journal of Pharmaceutical Sciences, 57, 121-125.

[37] Vedavathy, S. and Rao, K.N. (1991) Antipyretic Activity of Six Indigenous Medicinal Plants of Tirumala Hills, Andhra Pradesh, India. Journal of Ethnopharmacology, 33, 193-196. https://doi.org/10.1016/0378-8741(91)90178-G 
[38] Chang, R.S., Ding, L., Chen, G.Q., Pan, Q.C., Zhao, Z.L. and Snith, K.M. (1991) Dehydrographolide Succinic Acid Monoester as an Inhibitor against the Human Immunodeficiency Virus. Proceedings of the Society for Experimental Biology and Medicine, 197, 59-66. https://doi.org/10.3181/00379727-197-43225

[39] Ramalingam, S., Karupannan, S. and Padmanaban, P. (2018) Anti-Dengue Activity of Andrographis paniculata Extracts and Quantification of Dengue Viral Inhibition by SYBR Green Reverse Transcription Polymerase Chain Reaction. Ayu, 39, 87-91.

[40] Puri, A., Saxena, R., Saxena, R.P., Saxena, K.C., Srivastava, V. and Tandon, J.S. (1993) Immunostimulant Agents from Andrographis paniculata. Journal of Natural Products, 56, 995-999. https://doi.org/10.1021/np50097a002

[41] Duke, J.A. and Atchley, A.A. (1984) Proximate Analysis. In: Christie, B.R., Ed., The Handbook of Plant Science in Agriculture, CRC Press, Inc., Boca Raton, 427-434.

[42] Nnam, N.M. and Onyeke, N.G. (2003) Chemical Compositions of Two Varieties of Sorrel Hibiscus sabdariffa L., Calyces and the Drinks Made from Them. Plant Foods for Human Nutrition, 58, 1-7. https://doi.org/10.1023/B:QUAL.0000040310.80938.53

[43] Ojokoh, A.O. (2006) Roselle Hibiscus sabdariffa Calyx Diet and Histopathological Changes in Liver of Albino Rats. Pakistan Journal of Nutrition, 5, 110-113. https://doi.org/10.3923/pjn.2006.110.113

[44] Adanlawo, I.G. and Ajibade, V.A. (2006) Nutritive Value of the Two Varieties of Roselle Hibiscus sabdariffa Calyces Soaked with Wood Ash. Pakistan Journal of Nutrition, 5, 555-557. https://doi.org/10.3923/pjn.2006.555.557

[45] Carvajal, O., Maria, D., Dremitriz, B., Flores, Z.O., Margaret, P. and Jones, H. (2012) Hibiscus sabdariffa L., Roselle Calyx, from Ethnobotany to Pharmacology. Journal of Experimental Pharmacology, 4, 25-39. https://doi.org/10.2147/JEP.S27974

[46] Olaleye, M.T. (2007) Cytotoxicity and Antibacterial Activity of Methanolic Extract of Hibiscus sabdariffa. Journal of Medicinal Plants Research, 1, 9-13.

[47] Chao, C. and Yin, M. (2008) Antibacterial Effects of Roselle Calyx Extracts and Protocatechuic Acid in Ground Beef and Apple Juice. Foodborne Pathogens and Disease, 6, 201-206. https://doi.org/10.1089/fpd.2008.0187

[48] Fullerton, M., Khatiwada, J., Johnson, U.S., David, S. and William, L.L. (2011) Determination of an Timicrobial Activity of Sorrel Hibiscus sabdariffa on E. coli O157:H7 Isolated from Food Veterinary and Clinical Samples. Journal of Medicinal Food, 14, 950-956. https://doi.org/10.1089/jmf.2010.0200

[49] Leung, W.T.W., Busson, F. and Jardin, C. (1968) Food Composition Table for Use in Africa. FAO, Rome, 306 p.

[50] Morton, J. (1987) Roselle in Fruits of Warm Climates. Web Publications Purdue University, Miami, 281-286. 


\section{Abbreviations}

KKM Ministry of Health Malaysia

TGA Therapeutic Goods Administration

ISO14001 International Standard Effective Environmental Management System

HACCP Hazard Analysis and Critical Control Points

ISO9001 International Standard Quality Management System

HALAL Certification of Muslim Food Standard

GMP Good Manufacturing Process

HCV Hepatitis C Virus

HBV Hepatitis B Virus

MNTD Maximum Nontoxic Dose

DENV Dengue Virus

MTT Colorimetric assay for assessing cell metabolic activity

RT-PCR Reverse transcription polymerase chain reaction

SARI Severe acute respiratory infection

DSHEA The Dietary Supplement Health and Education Act of 1994

FDAU.S. Food and Drug Administration

WHO World Health Organization 